\title{
Experimental Study of the Scour Regimes Downstream of an Apron for Intermediate Tailwater Depth Conditions
}

\author{
P. Espa ${ }^{1}$ and S. Sibilla ${ }^{2 \dagger}$ \\ ${ }^{1}$ Dipartimento di Scienza e Alta Tecnologia, Università dell'Insubria, via G.B. Vico, 46, Varese, 21100, Italy \\ ${ }^{2}$ Dipartimento di Ingegneria Civile e Architettura, Università di Pavia, via Ferrata, 3, Pavia, 27100, Italy
}

†Corresponding Author Email: stefano.sibilla@unipv.it

(Received June 24, 2013; accepted November 8, 2013)

\begin{abstract}
The local scour of a non-cohesive bed due to a 2-D submerged horizontal jet is investigated experimentally in presence of a protection apron. Previous researches conducted without protection apron demonstrate that, when the tailwater depth is either deep or shallow, the equilibrium state characteristics of the scoured bed profile are mainly a function of the densimetric Froude number. However, when the submergence is between these two extremes, at fixed Froude number, three different scour regimes are possible. For relatively shallow tailwater depths, the jet mainstream directs towards the free surface (surface jet scouring regime), determining shallow and elongated scour profiles. For relatively large tailwater depths, the jet remains attached to the channel bottom (bed jet scouring regime), leading to deeper and shorter scour profiles. For intermediate conditions, the flicking of the jet between the erodible bed and the water free-surface is possible. When this instability occurs, the shape of the scour hole rapidly changes as a response of the jet mainstream position (bed-surface jet scouring regime). This paper aims to give an experimental description of the three mentioned regimes when a protection apron partly reduces the action of the flow on the loose bed. Scour hole profile evolution and velocity profile measurements obtained by LDA and ADV velocimetry are discussed.
\end{abstract}

Keywords: Local scour, Non cohesive bed, Protection apron, Submerged jet, Open channel flow, LDA velocity measurements, ADV velocity measurements.

\section{NOMENCLATURE}

$\begin{array}{ll}c_{c} & \text { contraction coefficient } \\ d_{g} & \text { grain size } \\ F_{0} & \text { Froude number } \\ g & \text { gravity acceleration } \\ h_{D} & \text { dune height } \\ h_{S} & \text { scour hole depth } \\ l & \text { apron length } \\ n & \text { sediment porosity } \\ Q & \text { flow rate } \\ q & \text { flow rate per unit width } \\ R e & \text { Reynolds number } \\ t & \text { time } \\ u & \text { streamwise velocity component } \\ u_{0} & \text { flow velocity at contraction }\end{array}$

\section{INTRODUCTION}

This paper describes an experimental investigation of the local scour caused by a two-dimensional (2D) horizontal wall-jet issuing from a sluice and developing on a rigid apron before interacting with a non-cohesive sand bed. Local scour downstream

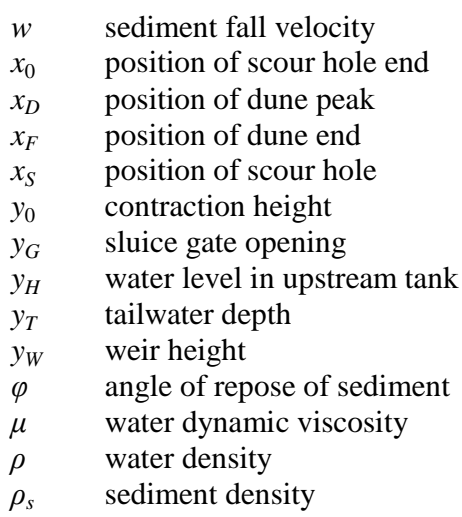

of hydraulic structures is extremely important in hydraulic engineering, because scour can hamper the stability of structures and induce their collapse if not properly accounted for. However, the correct prediction of local scour phenomena can be extremely difficult, owing to the complex interaction between the turbulent flow and the 
granular material of the bed. Recent advances in the numerical modeling of scouring show promising results obtained by using various techniques (see, for instance: Adduce and Sciortino, 2006; Vollmer and Kleinhans, 2007; Sibilla and Espa, 2008; Sibilla, 2008; Souza et al., 2010; Manenti et al., 2012), but the use of Computational Fluid Dynamycs (CFD) as a practical engineering tool is still questionable.

The design of hydraulic structures leans therefore upon empirical formulae which predict maximum scour depth and length and are based on experimental observation (see, as reference: Breusers and Radukivi, 1991; Hoffmans and Verheij, 1997). However, the range of validity of these formulae may not cover all of the possible cases which are found in reality.

The present research highlights a particular case of scouring under intermediate tailwater depth conditions, where the available practical formulae do not yield satisfactory results. Owing to its complexity, this scouring case can also be viewed as a challenging benchmark for CFD applications.

A sketch of the channel, together with the symbols adopted to indicate the main geometric variables of the problem, is given in Fig. 1: $l$ is the length of the apron, $y_{H}$ the water level in the upstream tank and $y_{G}$ the opening of the sluice gate generating the wall jet, $y_{0}$ is the height of the flow contraction downstream of the sluice, $y_{T}$ is the tailwater depth and $y_{W}$ is the height of the downstream weir. At any time $t$, the scour hole has maximum depth $h_{S, \max }$ and is located at distance $x_{S, \max }$ downstream of the of the apron; the dune developing downstream of the scour hole has peak located at $x_{D, \max }$ and $y_{D, \max }$. Finally, $x_{0}$ and $x_{F}$ are respectively the positions where the scour hole and the ridge end.

Any generic dimensional feature $\chi$ of the examined flow can be expressed as a function of nine parameters defining the flow and the bed (Ali and Lim 1986):

$\chi=\chi\left(u_{0}, g\left(\rho_{s}-\rho\right), \rho, \mu, y_{0}, y_{T}, l, d_{g}, t\right)$

where $u_{0}$ is the jet velocity at the contractionsection, $\rho_{s}$ and $\rho$ are the densities of sediments and water, $\mu$ is the dynamic viscosity of water, $d_{g}$ is a characteristic size of the sand grains and $g$ is gravity acceleration. Assuming asymptotic steady-state conditions, the non-dimensional representation $N_{\chi}$ of the generic feature $\chi$ can therefore be written in terms of five non-dimensional groups:

$N_{\chi}=N_{\chi}\left(u_{0} / \sqrt{\frac{\Delta \rho}{\rho} g d_{g}}, \frac{\rho u_{0} y_{0}}{\mu}, \frac{y_{T}}{y_{0}}, \frac{l}{y_{0}}, \frac{d_{g}}{y_{0}}\right)$

where $\Delta \rho=\left(\rho_{S}-\rho\right)$, while the terms in brackets are respectively the densimetric Froude number $F_{0}$, the Reynolds number $R e$, the relative submergence, the relative length of the apron and the roughness.

A general understanding of the process and a quantitative identification of the relevant parameters has been obtained by Rajaratnam (1981) for deeply submerged $2 \mathrm{D}$ jets (i.e. when $y_{T} \gg y_{0}$, being at least $\left.y_{T} / y_{0}>10\right)$ and by Rajaratnam and Mac Dougall (1983) for 2D jets with minimum tailwater (i.e. $y_{T} \approx y_{0}$ ). These studies showed that, when the protection apron is absent, the tailwater depth is either relatively deep or very shallow and the effect of viscosity $(R e>3000)$ and relative roughness can be neglected $\left(d_{g} / y_{0} \ll 1\right)$, the asymptotic-state characteristics of the eroded bed profile are essentially functions of $F_{0}$. In particular, for a fixed value of $F_{0}$, the maximum scour depth at equilibrium $h_{S, \max , \infty}$ is larger for deeply submerged cases.

Aderibigbe and Rajaratnam (1998) extended the work by Rajaratnam (1981) to non-uniformly graded sediments and demonstrated that the nonuniformity has a noticeable effect on the size of the scour hole produced by the jet, as armoring acts to significantly reduce the maximum scour depth and dune height. The best correlation for the depth of the scour hole was obtained in this case when $d_{95}$, rather than $d_{50}$, was adopted as effective size of the sediment mixture in the definition of $F_{0}$. Here and in the following, the notation $d_{x}$ indicates as usual the grain size larger than that of the $x \%$ by weight of a sediment mixture.

Conditions of intermediate submergence (approximately $1<y_{T} / y_{0}<10$ ) have been experimentally analyzed by Ali and Lim (1986), who, for fixed $F_{0}$ values, showed that the asymptotic scour depth depends on the tailwater depth and that a critical tailwater depth exists, beyond which an increase or decrease in tailwater causes an increase in $h_{S, \max , \infty}$ For $y_{T} / y_{0}>16$ (which, strictly speaking, should be assumed as the lower limit for deeply submerged jets), a constant value of $h_{S, \max , o d} y_{0}$ is approached, i.e. the effect of tailwater becomes negligible. Ali and Lim (1986) also showed that, at relatively large tailwater depths $\left(y_{T} / y_{0}>10\right)$, an asymptotic depth of scour is reached in a continuous manner, while at lower tailwater depths $\left(y_{T} / y_{0}<5\right)$ the scatter of data suggests that the scour hole does not undergo a continuous growth to asymptotic conditions.

Johnston and Halliwell (1987) noted that the maximum spread of the results obtained by Ali and Lim (1986) occurs in the region where both the densimetric Froude number and the flow depth are small $\left(F_{0}<5 ; y_{T} / y_{0}<5\right)$. They suggest that this behavior indicates the presence of a discontinuity in the scour process under these flow conditions, in accordance with their findings on 2D turbulent jets in a rigid bed channel (Johnston and Halliwell 1986). In fact, in this case the jet attaches itself permanently to the bed (bed jet regime) or to the free surface (surface jet regime), depending on the relative submergence; furthermore, for some values of the tailwater depth, both the mentioned configuration may occur intermittently.

Johnston (1990) considered a plane jet entering horizontally a channel from a slot higher than the undisturbed bed level. He showed that, in shallow tailwater conditions, the jet can produce three different scouring regimes: two regimes are related to bed-jet and surface-jet flow patterns, while the 
third one is produced when the jet periodically flicks between the free and solid bed boundaries (bed-surface jet regime). When $F_{0}$, bed roughness, and slot offset are held constant, the onset of the different regimes depends only on the submergence depth.

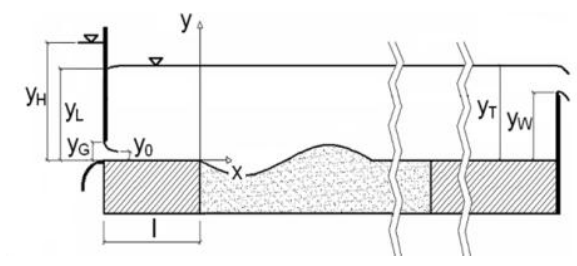

(a)

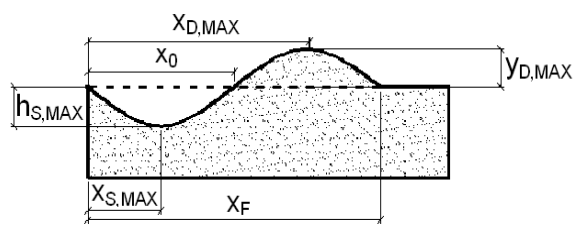

(b)

Fig. 1. Sketch of the experimental channel with the adopted reference system $(x, y$ axes) and the main adopted geometric symbols.

At the largest tailwater depths, the jet mainstream clearly flows along the erodible bed: a scour profile with a ridge positioned just downstream of the hole develops very quickly; this can be defined as a bed jet scouring regime, and has been described by Rajaratnam (1981) and Nik Hassan and Narayanan (1985).

At the smallest tailwater depths, a different scour pattern develops: the hole is less deep and more elongated in the streamwise direction, than in the bed jet case, while the ridge is lower and tends to move downstream fairly quickly. In this case the jet is shifted towards the free surface and the scour development can be therefore defined as a surface jet scouring regime. The characteristics of the scour hole are in this case similar to those described by Rajaratnam and Mac Dougall (1983).

At intermediate depths, the jet appears to be initially attached to the bed; however, at some time this configuration becomes unstable, the jet shifts towards the surface and the scour hole starts to fill in as the downstream mound slumps back into the hole. Just as this pattern begins to stabilize, a further sudden change leads to the re-establishment of the bed jet regime. This scour hole development is identified as a bed-surface jet scouring regime. The flicking of the jet from one boundary to another appears to be dependent on the relative stability of the two patterns. When one of the patterns (bed or surface jet) is more stable than the other one, the flick to the other boundary is for a very short period (few seconds) and is fairly random. The flicking phenomenon described by Johnston (1990) has a cycling period between 2-27 min where the jet alternates between boundaries. The period of cycling seems to increase with the tailwater submergence: the larger the submergence, the longer (on average) the time the jet is located on the bed during each cycle.

The effect of different scouring regimes on scouring rate may be important in practical engineering applications. Johnston (1990) notes that an increase in time results in an increase in the maximum scour hole depth, both in the bed jet and the surface jet regimes; the scouring rate in the surface jet case appears to be lower than the corresponding rate in the bed jet regime. In the bed-surface jet regime, the scour hole depth varies owing to the transient nature of the flow, but its magnitude remains relatively constant. The influence of submergence on the scour hole depth also depends on the regime: while in the bed jet regime an increase in submergence produces an increase in scour depth, in the surface jet regime the scour depths remain relatively constant. In the bed-surface jet regime the trends are less definite but, on average, a higher submergence leads to deeper scour holes. A similar behavior was found also by Adduce and La Rocca (2006) and Adduce and Sciortino (2006) when investigating the scour downstream of a trapezoidal drop.

Previous works on localized scour due to submerged 2D wall jets downstream of protection aprons (Chatterjee and Ghosh 1980, Nik Hassan and Narayanan 1985, Chatterjee et al. 1994, Dey and Sarkar 2006, 2008) do not report different scour hole developments when varying the relative tailwater depth. However, Chatterjee and Ghosh (1980), while performing experiments on two erodible beds of different grain size (sand and gravel), report a jet oscillation and a break-down of the scour profile immediately after reaching the equilibrium stage, during an experiment in deep submergence conditions $\left(y_{T} / y_{0}=15.5\right)$ and $F_{0} \approx 9$.

The present paper focuses on the description of the different scouring regimes due to a jet issuing from a vertical sluice gate, when the erodible bed is located downstream of a protection apron. Several tests have been performed and the onset of the three regimes described by Johnston (1990) has been verified also when the apron is present. Three experiments have been selected as representative of the different scouring regimes, and the evolution of the bed profile and flow pattern has been investigated in detail in these cases.

\section{EXPERIMENTAL SET-UP}

The experiments were performed in a horizontal glass-paneled channel installed in the Hydraulics Laboratory of the University of Pavia. The channel is $4.5 \mathrm{~m}$ long, $0.102 \mathrm{~m}$ wide and $0.44 \mathrm{~m}$ deep. A 2.5 $\mathrm{m}$ long and $0.2 \mathrm{~m}$ deep bed of non-cohesive sediments was disposed between two steel boxes: the length of the upstream one (representing the rigid apron) was varied during experiments $(l=$ 0.25 and $0.5 \mathrm{~m})$, while the downstream one $(1.5 \mathrm{~m}$ long) was kept fixed.

Figure 1 shows a sketch of the sharp-edged sluicegate regulating the water inlet in the channel from 
an upstream constant-head reservoir; this reservoir is $0.8 \times 1.2 \mathrm{~m}$ in plan. It is fed by the constanthead water tank of the Laboratory, through a pipe having a diameter of $0.1 \mathrm{~m}$, in order to avoid high velocities in the reservoir; a turbulence-damping steel grid was also used to reduce turbulence levels at the tank inflow.

Measurement of the flow-rate was obtained by an electromagnetic flow-meter (Automation Progetti AP 1018LZ6), with $\pm 0.2 \%$ accuracy at the maximum flow rate of $0.011 \mathrm{~m}^{3} / \mathrm{s}$. Downstream of the flow-meter, along the pipe connecting the experimental channel to the Laboratory hydraulic circuit, two control valves (the downstream one for finer regulation) were installed. At the tank outlet, the lower and lateral sides of the hole in the tank wall are equipped with streamlined (circumferencearc) steel profiles in order to obtain only a vertical contraction of the flow entering the channel. Consequently, no lateral contraction takes place, and the classical formula $y_{0}=c_{c} y_{G}$ may be applied, where $c_{c}$ is a contraction coefficient. The water depths in the channel are controlled by a sharpedged Bazin weir whose height $y_{W}$ on the channel bottom may be regulated; the weir is located at the downstream end of the channel (Fig. 1).

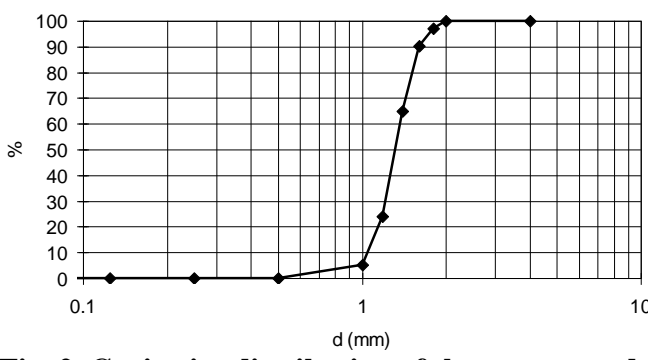

Fig. 2. Grain size distribution of the coarse sand used in the experiments.

An approximately uniform-sized coarse sand was used in the experiments. The grain size distribution of a sample of the sand was measured at the Geology Laboratory of the University of Pavia (Fig. 2).

The reference values for the distribution are $d_{10}=$ $1.05 \mathrm{~mm}, d_{50}=1.32 \mathrm{~mm}$ and $d_{90}=1.6 \mathrm{~mm}$. The sand is characterized by a porosity $n=0.45$, a density $\rho_{\mathrm{s}}=2650 \mathrm{~kg} / \mathrm{m}^{3}$, an angle of repose $\varphi=30^{\circ}$ and a mean fall velocity $w=0.13 \mathrm{~m} / \mathrm{s}$.

Experimental observations were conducted using different techniques:

- A rack of wool-wires placed in the mid-section of the channel, in order to visually show the main characteristics of the flow pattern;

- A digital photo-camera to collect images both of the wool-wire visualizations and of the scour profiles; these bed profiles images have been processed to obtain quantitative measurements of the evolution of the bottom shape;

- A Laser Doppler Anemometer (LDA) to measure profiles of the horizontal velocity component $U$ in the mid-plane of the channel;

-A pulsed ultrasound Acoustic Doppler Velocimeter (ADV) to measure the velocity component along the probe axis in several point simultaneously.

The LDA system is a single component backscattering TSI-LDP 100 equipped with a lens having a focal length of $250 \mathrm{~mm}$. The $50 \mathrm{~mW}$ Laser-diode source generates a $694 \mathrm{~nm}$ wavelength light; the measuring volume is about $0.03 \mathrm{~mm}^{3}$ and has approximately the shape of an ellipsoid with symmetry axis normal to the $x-y$ plane. No seeding was used: the particles dispersed in the water of the closed-circuit of the Laboratory allowed for goodquality signal collection. The acquired signal was processed with a completely PC-assisted processor (TSI-IFA 600) using a dedicated software package (TSI-Laservec 1.0). Each velocity measure includes no less than 5000 samples and lasts for at least $60 \mathrm{~s}$, in order to stabilize the time averaged value of the signal; thus, at high sampling rates, the number of acquired samples exceeded (even by 5 times) the mentioned 5000 samples.

The ADV system (Signal Processing DOP 1000) is equipped with a $4 \mathrm{MHz}$ ultrasound emitter/transducer. The pulse repetition frequency (PRF) has been varied between 3.125 and $5.95 \mathrm{kHz}$, depending on the maximum measurable depth needed; the vertical resolution varied between 1.4 and $2.1 \mathrm{~mm}$. In this case the flow was seeded by fine clay particles to collect good quality signals. Each velocity profile was obtained by averaging no less than 6000 samples collected for at least $120 \mathrm{~s}$. In quasi steady-state conditions (sections 3.1 and 3.2 ), horizontal velocity profiles were computed from two non-simultaneous measurements taken with the ADV probe axis forming an angle of $60^{\circ}$ and $70^{\circ}$ with the horizontal plane. In unsteady conditions (section 3.3 ), horizontal velocity profiles were computed by deducing from wool-wire visualizations the average inclination angle of the velocity vector.

Both LDA and ADV measurements were carried out more than 8 hours after the starting of the tests: as explained in the following, after 8 hours the evolution of the eroded bed was slow enough not to alter in a meaningful way the velocity field during the execution of the measurements. These velocity measurements may therefore be intended as the equilibrium state ones. As previously said, the velocity measurements were conducted in the vertical symmetry plane of the flow; more generally, the phenomenon has been investigated as a 2D one. This approximation appeared reasonable because (1) the patterns of the eroded bed (both of the scour hole and the dune) are essentially twodimensional (see following sections) and (2) the flow-rates computed by integrating the vertical profiles of the horizontal velocity component (both LDA and ADV) are generally in good agreement with those measured by the electro-magnetic flowmeter.

Only clear-water scour conditions (i.e. no sediment supply from upstream) were investigated; moreover, downstream of the scour hole-dune region, no sediment motion was observed: this was also confirmed by a classical Shields estimate. 


\section{ANALYZED CASES}

The sluice opening $y_{G}$, the weir height $y_{W}$ (and consequently the tailwater depth $y_{T}$ ), the apron length $l$ and the flow rate $Q$ were varied throughout the investigation. Each reported test lasted for at least 8 hours. In general, no asymptotic equilibrium was reached at the end of the tests: as noted by Nik Hassan \& Narayanan (1985), asymptotic conditions need a very long time to be reached when the vertical scales of the bed profile (particularly the dune height) are, as in the present case, comparable to the submergence.

The main parameters characterizing the 24 tests discussed in the present paper are listed in Table 1, ordered by run number. The average value of the water level just downstream of the sluice, where a submerged hydraulic jump takes place, is indicated by $y_{L}$. In the tests where the difference $y_{T}-y_{L}$ is larger, the free surface oscillates due to the submerged jump, and $y_{T}$ values are here given as time-averaged ones.

In Table 1, the last column to the right indicates the scour regime which characterizes the test: surface jet (S), bed jet (B), slightly unstable bed jet (UB) and bed-surface jet flicking regime (F); the symbol - indicates that no grain motion takes place on the flume bottom.

The contraction coefficient $c_{c}$ has been estimated from the measured values of $Q$ and $y_{H}-y_{L}$ by assuming energy conservation across the sluice. The values of $y_{0}$ and $u_{0}$ have been calculated accordingly. Some $u_{0}$ values have been checked against available LDA velocity measurements.

Table 1 Test parameters

\begin{tabular}{|c|c|c|c|c|c|c|c|c|c|c|c|c|c|c|c|}
\hline Run & $Q$ & $l$ & $y_{W}$ & $y_{G}$ & $y_{L}$ & $y_{T}$ & $y_{H}$ & $y_{0}$ & $c_{c}$ & $u_{0}$ & $R e$ & $F_{0}$ & $y_{T} / y_{0}$ & $l / y_{0}$ & regime \\
\hline & {$[1 / \mathrm{s}]$} & {$[\mathrm{mm}]$} & {$[\mathrm{mm}]$} & {$[\mathrm{mm}]$} & {$[\mathrm{mm}]$} & [mm] & {$[\mathrm{mm}]$} & $\mathrm{mm}]$ & {$[-]$} & {$[\mathrm{m} / \mathrm{s}]$} & {$[-]$} & {$[-]$} & {$[-]$} & {$[-]$} & {$[-]$} \\
\hline 1 & 2 & 250 & 74 & 40 & 111 & 120 & 136 & 28 & 0.70 & 0.70 & 19600 & 4.4 & 4.3 & 8.9 & $\mathrm{~F}$ \\
\hline 2 & 2 & 250 & 140 & 40 & 183 & 186 & 212 & 26 & 0.65 & 0.75 & 19500 & 4.7 & 7.2 & 9.6 & B \\
\hline 3 & 2 & 250 & 140 & 80 & 186 & 186 & 192 & 57 & 0.71 & 0.34 & 19400 & 2.1 & 3.3 & 4.4 & - \\
\hline 4 & 3 & 250 & 74 & 40 & 116 & 134 & 176 & 27 & 0.68 & 1.08 & 29200 & 6.7 & 4.9 & 9.2 & $\mathrm{~F}$ \\
\hline 5 & 3 & 250 & 140 & 40 & 193 & 200 & 255 & 27 & 0.67 & 1.10 & 29700 & 6.9 & 7.5 & 9.4 & $\mathrm{~F}$ \\
\hline 6 & 3 & 250 & 140 & 80 & 198 & 200 & 212 & 56 & 0.70 & 0.52 & 29100 & 3.3 & 3.6 & 4.5 & UB \\
\hline 7 & 4 & 250 & 74 & 40 & 117 & 145 & 224 & 27 & 0.68 & 1.45 & 39200 & 9.0 & 5.4 & 9.2 & $\mathrm{~F}$ \\
\hline 8 & 4 & 250 & 140 & 40 & 198 & 211 & 306 & 27 & 0.67 & 1.46 & 39400 & 9.0 & 7.8 & 9.3 & $\mathrm{~F}$ \\
\hline 9 & 4 & 250 & 140 & 80 & 207 & 211 & 232 & 56 & 0.70 & 0.70 & 39200 & 4.4 & 3.8 & 4.5 & $\mathrm{~F}$ \\
\hline 10 & 2 & 500 & 74 & 40 & 116 & 120 & 139 & 29 & 0.73 & 0.67 & 19400 & 4.2 & 4.1 & 17.1 & $S$ \\
\hline 11 & 2 & 500 & 140 & 40 & 183 & 186 & 208 & 28 & 0.70 & 0.70 & 19600 & 4.4 & 6.6 & 17.9 & UB \\
\hline 12 & 2 & 500 & 140 & 80 & 186 & 186 & 191 & 63 & 0.78 & 0.31 & 19500 & 1.9 & 3.0 & 8.0 & - \\
\hline 13 & 3 & 500 & 74 & 40 & 118 & 134 & 182 & 26 & 0.65 & 1.12 & 29100 & 7.0 & 5.1 & 19.1 & $S$ \\
\hline 14 & 3 & 500 & 140 & 40 & 190 & 200 & 254 & 26 & 0.66 & 1.12 & 29100 & 7.0 & 7.6 & 19.0 & $\mathrm{~F}$ \\
\hline 15 & 3 & 500 & 140 & 80 & 195 & 200 & 209 & 56 & 0.70 & 0.52 & 29100 & 3.3 & 3.6 & 8.9 & B \\
\hline 16 & 4 & 500 & 74 & 40 & 116 & 145 & 223 & 27 & 0.68 & 1.45 & 39200 & 9.0 & 5.4 & 18.5 & $S$ \\
\hline 17 & 4 & 500 & 140 & 40 & 194 & 211 & 302 & 27 & 0.67 & 1.46 & 39400 & 9.0 & 7.8 & 18.6 & $\mathrm{~F}$ \\
\hline 18 & 4 & 500 & 140 & 80 & 204 & 211 & 230 & 55 & 0.69 & 0.71 & 39100 & 4.4 & 3.8 & 9.1 & UB \\
\hline 19 & 1.15 & 250 & 180 & 35 & 213 & 214 & 226 & 22 & 0.65 & 0.52 & 11400 & 3.3 & 9.6 & 11.2 & B \\
\hline 20 & 2.15 & 250 & 170 & 35 & 216 & 220 & 260 & 23 & 0.71 & 0.93 & 21400 & 5.8 & 9.7 & 11.0 & B \\
\hline 21 & 3.5 & 250 & 150 & 35 & 210 & 217 & 325 & 23 & 0.60 & 1.52 & 35000 & 9.6 & 9.5 & 10.9 & $\mathrm{~F}$ \\
\hline 22 & 1.5 & 250 & 180 & 45 & 218 & 218 & 231 & 29 & 0.66 & 0.52 & 15100 & 3.3 & 7.5 & 8.6 & B \\
\hline 23 & 2.8 & 250 & 35 & 45 & 79 & 90 & 122 & 30 & 0.68 & 0.93 & 27900 & 5.8 & 3.0 & 8.4 & S \\
\hline 24 & 4.1 & 250 & 35 & 45 & 78 & 104 & 171 & 30 & 0.67 & 1.37 & 41100 & 8.6 & 3.5 & 8.4 & S \\
\hline
\end{tabular}

The $d_{90} / y_{0}$ ratio ranges from 0.03 to 0.06 in all the reported experiments. Each test was started from rest, the water depth in the tank and in the channel being equal to $y_{W}$. When the flow-rate $Q$ was almost impulsively discharged in the tank, the water levels $y_{H}$ and $y_{T}$ approached quickly their steady-state values. The influence of the start-up phase on the scour development was therefore negligible. Bed profile evolution and overall flow pattern in tests $13,14,15$ are discussed in the following to highlight the characteristics of each detected regime. 


\section{Stable REgimes}

\subsection{Surface Jet Scouring Regime}

In tests no. 10, 13 and 16, the jet mainstream directs towards the free-surface just downstream of the apron, as marked by the blowing up on the freesurface which is clearly visible during the experiments.

The flow pattern is deduced from wool-wire visualizations (Fig. 3.a) and is sketched in Fig. 3.b. It is characterized by two counter-rotating vortices: the submerged hydraulic jump and the separation vortex just downstream of the apron. This flow pattern is typical of the flow issuing from a sluice gate in several other applications, such as settling tanks (Razmi et al., 2009).

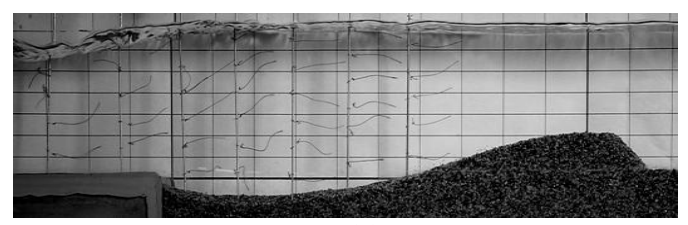

(a)

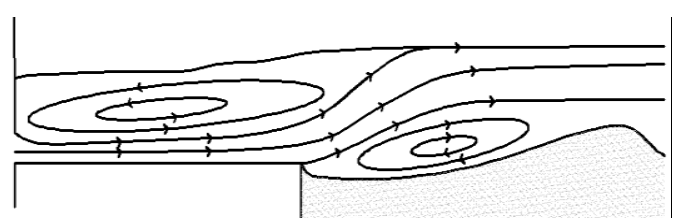

(b)

Fig. 3. Flow visualization and flow-pattern for surface jet scouring regime:

(a) wool-wire flow visualization (test no. 13, $t=$ $7200 \mathrm{~s}$ );

(b) sketch of the flow-pattern.

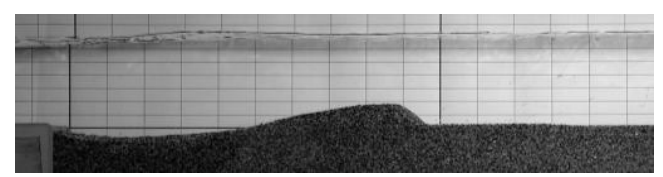

(a)

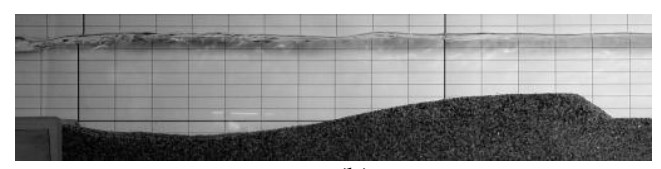

(b)

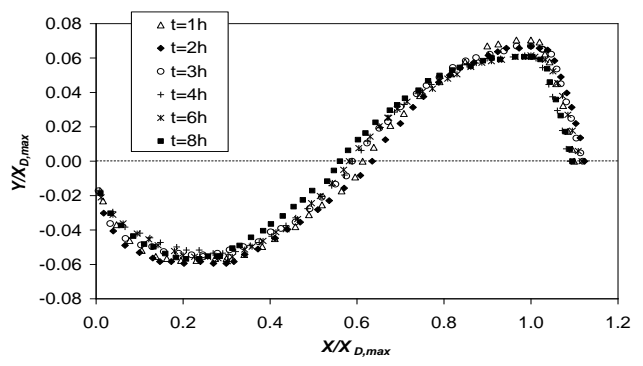

(c)

Fig. 4. Erodible bed profile for test no. 13 (surface jet scouring regime). Images of the bed profile: (a) $t=3600 \mathrm{~s}$; (b) $t=28800 \mathrm{~s}$.

(c) Normalized bed profiles at different times.
Regardless of the evolution of the bed (and therefore of the horizontal size of the two vortices, in particular the lower one) the described flow pattern remains the same during the whole run. The resulting "elongated" shape of the bed profile is characterized by relatively small vertical scales $\left(h_{S, \max }\right.$ and $\left.y_{D, \max }\right)$ and relatively large horizontal scales $\left(x_{S, \max }, x_{0}, x_{D, \max }, x_{F}\right)$.

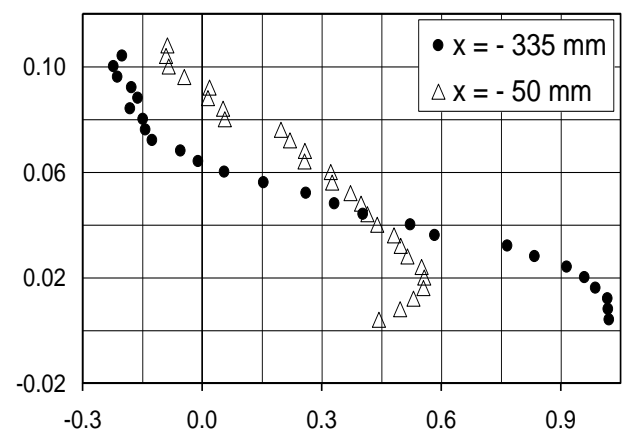

(a)

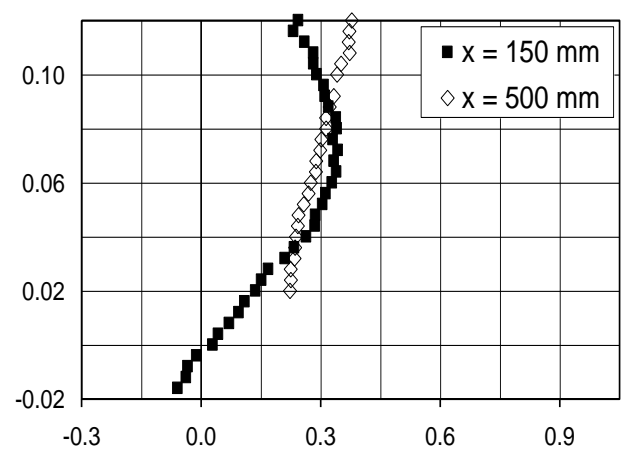

(b)

Fig. 5. LDA vertical profiles of $u$ (in $\mathrm{m} / \mathrm{s}$ ) vs. $y$ (in m) at different $x$ positions for test no. 13: (a) $x / l=-0.66$ and $x / l=-0.1$ located above the apron; (b) $x / l=0.3$ and $x / l=1$, located on scour hole and dune.

An example is given in Fig. 4, where two images of the bed profile 1 and 8 hours after the beginning of run no. 13 are shown (as in the following photographs, the vertical grid spacing behind the flow is $20 \mathrm{~mm}$ and the horizontal one is $50 \mathrm{~mm}$ ).

In Fig. 4.c the non-dimensional bed profiles derived at various times by image-processing are plotted, adopting $x_{D, \max }$ as the length scale both in the horizontal and vertical directions, as suggested by Nik Hassan and Narayanan (1985): after an initial transient of roughly 30 minutes, and apart from a small trend in reducing vertical normalized scales, the profile similarity is evident.

The vertical profiles of time-averaged horizontal velocity $u$, measured by LDA, confirm the described flow pattern. For instance, Fig. 5 shows the velocity profiles collected during run no. 13 . Above the wall jet, the detected zone of backflow (Fig. 5.a) highlights the presence of the submergedjump roller, which extends along the whole apron length. 
The $u$ profile on the scour hole (Fig. 5.b, $x=150$ $\mathrm{mm}, x / l=0.3$ ) displays near the bed a small backflow region, connected to the separation vortex downstream of the apron; the position of the maximum $u$ value near the free surface confirms the behavior of the jet mainstream. Further downstream the velocity profile becomes more regular, almost linear, with maximum close to the free-surface (Fig. 5.b, $x=500 \mathrm{~mm}$ ).

\subsection{Bed Jet Scouring Regime}

In tests no. 2, 15, 19, 20 and 22, the jet mainstream remains attached to the channel bed downstream of the apron and the free-surface appears to be only slightly perturbed. Runs 6, 11 and 18 show essentially the same behavior, although a displacement of the jet towards the free surface can be noticed for relatively short periods.

The flow pattern deduced from wool-wire visualizations (Fig. 6.a) is sketched in Fig. 6.b and is again characterized by two counter-rotating vortices. The submerged jump roller extends up to above the sand bed, further downstream than in previously discussed case. The vortex due to the boundary-layer separation from the apron edge is considerably smaller than in the previous case; nevertheless, its presence is clearly highlighted by sand motion. When compared to the surface jet case, the bed profile is characterized by larger vertical scales $\left(h_{S, \max }\right.$ and $\left.y_{D, \max }\right)$ and smaller horizontal scales $\left(x_{S, \max }\right.$ and $\left.x_{D, \max }\right)$.

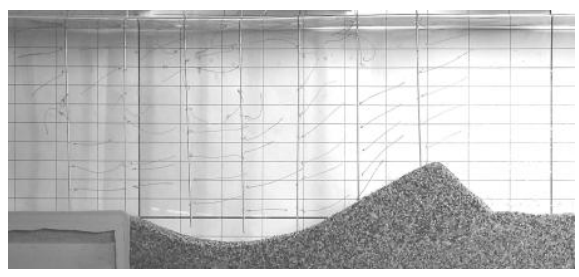

(a)

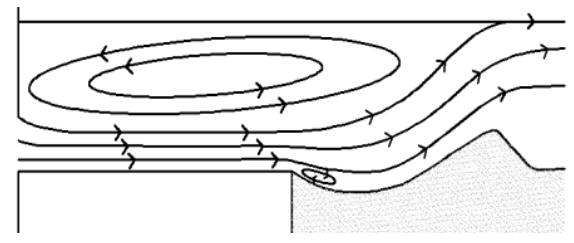

(b)

Fig. 6. Flow visualization and flow-pattern for bed jet scouring regime: (a) wool-wire flow visualization (test no. 15, $t=5400 \mathrm{~s}$ ); (b) sketch of the flow-pattern.

Figure 7.a and Fig. 7.b show two images of the bed 1 and 7 hours after the start of run no. 15. Bed profiles at different times, made non-dimensional by $x_{D, \max }$, are shown in Fig. 7.c: excluding the initial transient of about 60 minutes, the profile similarity is even more evident than in the surface jet case. Also in the bed jet regime, the flow pattern is confirmed by LDA measurements of time-averaged horizontal velocity $u$. Figure 8 shows velocity profiles measured during run no. 15. It must be noted that only ADV measurements could be obtained above the erodible bed, owing to a slight unsteadiness of the flow. However, the comparison between LDA and ADV measurements at $x=-50$ $\mathrm{mm}$ (Fig. 8.a) shows the reliability of ADV measures.

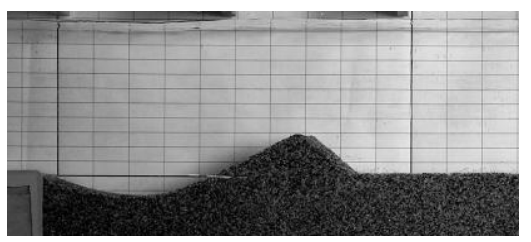

(a)

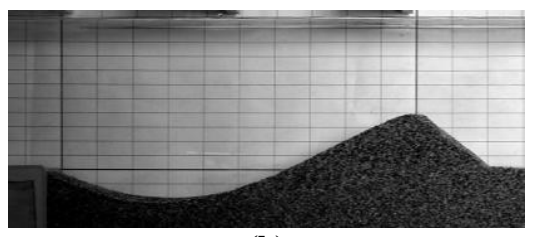

(b)

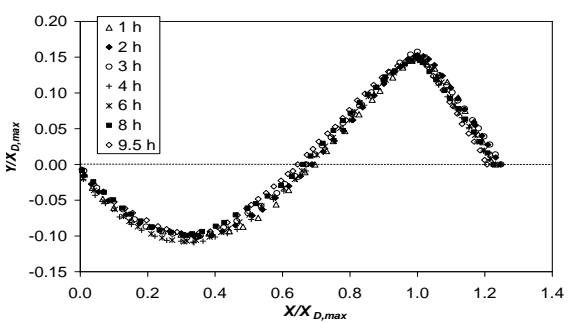

(c)

Fig. 7. Erodible bed profile for test no. 15 (bed jet scouring regime). Images of the bed profile:

(a) $t=3600 \mathrm{~s}$; (b) $t=25200 \mathrm{~s}$. (c) Normalized bed profiles at different times.

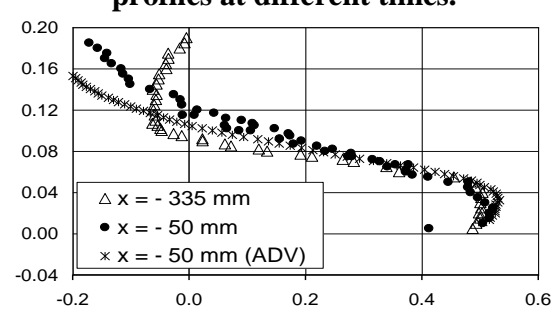

(a)

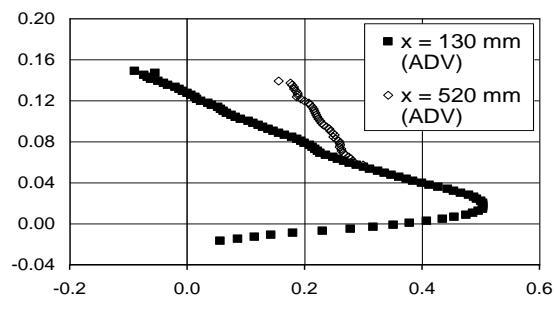

(b)

Fig. 8. LDA and ADV vertical profiles of $u$ (in $\mathrm{m} / \mathrm{s}$ ) vs. $y$ (in $\mathrm{m}$ ) at different $x$ positions for test no. 15: a) $x / l=-0.66$ and $x / l=-0.1$ located above the apron b) $x / l=0.26$ and $x / l=1$, located on scour hole and dune. 
The velocity profiles shown in Fig. 8.b confirm that downstream of the apron the jet flows along the scour hole. Above the dune crest, the flow shows again an almost linear velocity profile, but its maximum value is now located close to the bed. Moreover, the backflow detected in the velocity profile measured at $x=130 \mathrm{~mm}$ shows that the submerged jump roller extends above the scour hole.

It should be underlined that, in the discussed experiment, the relatively small $l / y_{0}$ ratio (i.e. $\approx 9$, see Table 1) prevents the wall jet from becoming fully-developed at the end of the apron. Actually, the maximum jet velocity at the end of the apron (profile at $x / l=-0.1$, Fig. 8.a) is still almost equal to the one measured just downstream of the sluice (profile at $x / l=-0.66$ ) and to the value $u_{0}=0.52$ $\mathrm{m} / \mathrm{s}$, which has been computed for run 15 by assuming energy conservation across the sluice (Table 1).

This behavior can be compared to the surface jet pattern described in Section 4.1. In run no. 13, the maximum velocity of the jet just downstream of the sluice (profile at $x / l=-0.66$, Fig. 5.a) is slightly larger than $1 \mathrm{~m} / \mathrm{s}$ and agrees well with the energyconservation estimate $u_{0}=1.12 \mathrm{~m} / \mathrm{s}$ (Table 1). When the jet approaches the loose bed (profile at $x / l$ $=-0.1$, Fig. 5.a), its maximum horizontal velocity is lower than $0.60 \mathrm{~m} / \mathrm{s}$, i.e. there is almost a $50 \%$ velocity decay along the apron. This decay appears to be much larger than the one expected for a simple 2D wall jet: applying, for instance, a semiempirical decay law for simple 2D turbulent wall jets (Rajaratnam, 1976), the maximum velocity reduction at $x / l=0$ for $l / y_{0}=19.1$ (i.e. for the present normalized apron length, see Table 1) should not be larger than $10 \%$. This difference with the plane jet behavior is the obvious consequence of the reverse flow detected above the jet.

The analysis of these stable regime cases demonstrates that the definition of the proper velocity scale for the scouring jet is not immediate: the classical results concerning plane wall jets cannot be applied when the submergence is not very deep (i.e. when the effect of the submerged jump on the jet development is not negligible).

Most of all, it must be noted that scour profiles are substantially different (Fig. 4 and Fig. 7) even when the jet velocities are approximately equal at the end of the apron (as in the mentioned case of runs no. 13 and 15, where the maximum velocity of the jet leaving the apron is about $0.5 \mathrm{~m} / \mathrm{s}$ ). In particular, after comparable elapsed time, the maximum scour $h_{S, \max }$ in run 15 (bed jet scouring regime) is about twice as deep than in run 13 (surface jet scouring regime).

\section{UNSTEADY FLOW}

Apart from the two stable regimes discussed in the previous section, an unsteady flow regime is also possible for intermediate tailwater depths. In this case, the jet flicks intermittently between its lower and the upper boundaries (the erodible bed and the free-surface, respectively). Tests no. 1, 4, 5, 7, 8, 9, 14, 17 and 21 (Table 1) are characterized by this unsteady behavior.

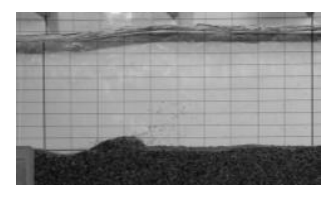

(a)

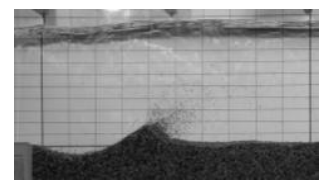

(b)

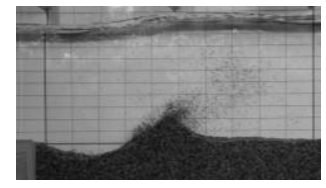

(c)

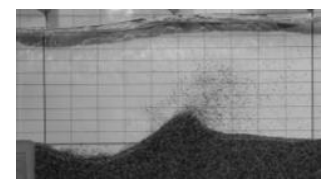

(d)

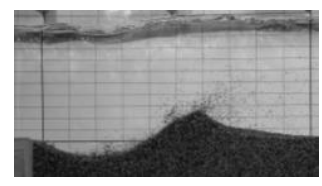

(e)

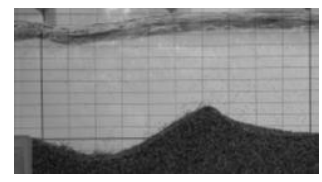

(f)

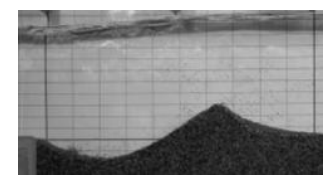

(g)

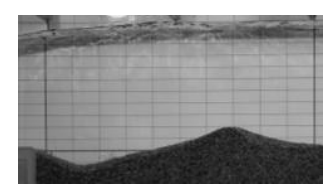

(h)

Fig. 9. Bed-surface jet regime: bed profile evolution during the 1st cycle in test no.14. a) $t=30 \mathrm{~s}$; b) $t=60 \mathrm{~s}$; c) $t=90 \mathrm{~s}$; d) $t=120 \mathrm{~s}$; e) $t=150 \mathrm{~s}$; f) $t=180 \mathrm{~s}$; g) $t=210 \mathrm{~s}$; h) $t=340 \mathrm{~s}$. 


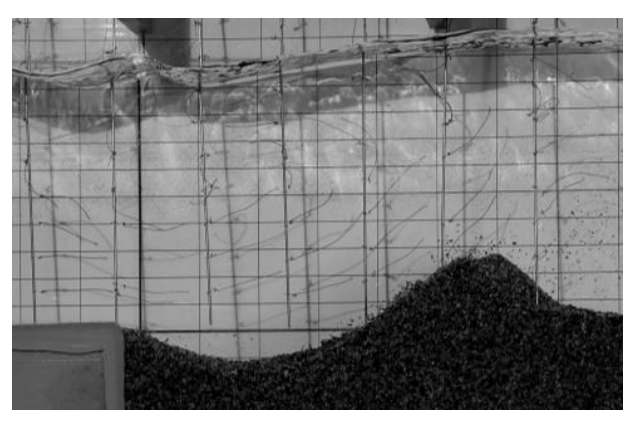

(a)

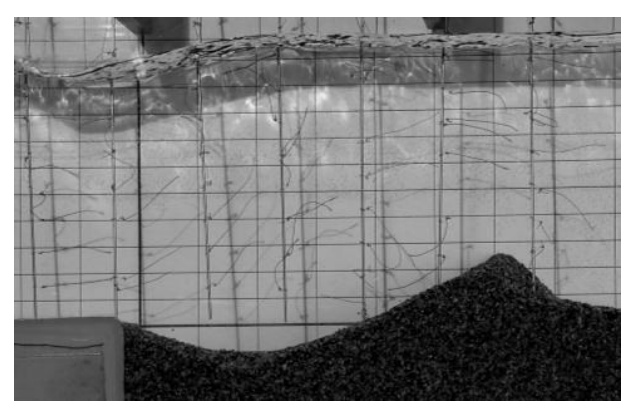

(b)

Fig. 10. Wool-wire flow visualizations for bedsurface jet scour hole regime (test no. 14): a) $t=240 \mathrm{~s}\left(1^{\text {st }}\right.$ cycle; bed jet phase $\left.) ; b\right) t=290 \mathrm{~s}\left(1^{\text {st }}\right.$ cycle; surface jet phase).

Figure 9 shows the initial transient phase of test no. 14. At the beginning of the test, the jet remains attached to the bed and generates the first scour hole and dune, which both rapidly increase in size; the strength of the scour process in this phase is evidenced by the bursting of sand grains under the effect of the jet flow (Fig. 9.b-e). During this period, the flow pattern is analogous to the bed jet case, as clearly evidenced in the wool-wire flow visualization in Fig. 10.a.

After a certain time has elapsed, the flow pattern suddenly shifts to the surface jet one, i.e. the jet mainstream suddenly detaches from the bed and moves towards the free surface, as shown in Fig. 10.b. As a consequence, the upstream side of the dune (whose slope had exceeded the repose angle under the effect of the jet flow) collapses into the scour hole and partly fills it, giving to the scour hole a typical cusp shape (Fig. 9.h), while the freesurface hump moves backwards, marking the displacement of the region of impact between jet and free surface (the submerged jump moves back too).

After a certain period of surface jet flow, the jet suddenly attaches to the bed and a new cycle starts: a strong scour process with sand bursting takes place again and a secondary dune arises. This dune, whose slope again exceeds the repose angle, grows and eventually reaches a height larger than the one of the main dune, until, at the end of the bed jet phase, the jet shifts again towards the free surface and the secondary dune collapses in the scour hole.

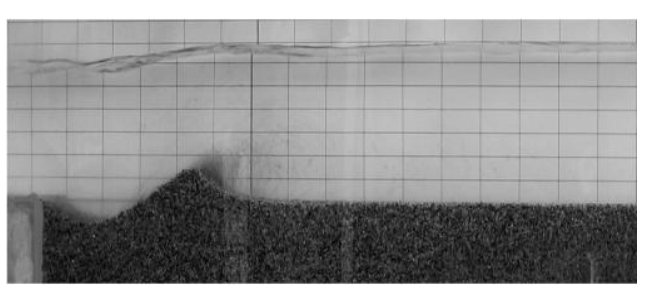

(a)

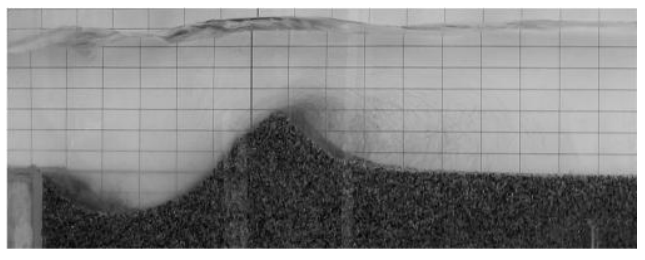

(b)

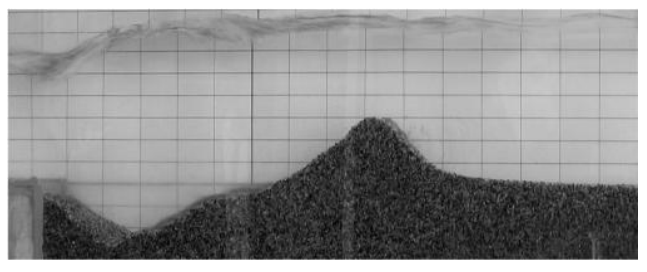

(c)

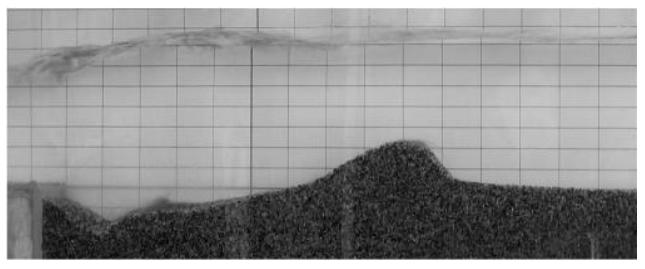

(d)

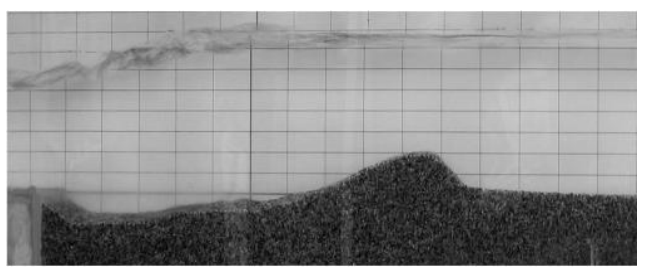

(e)

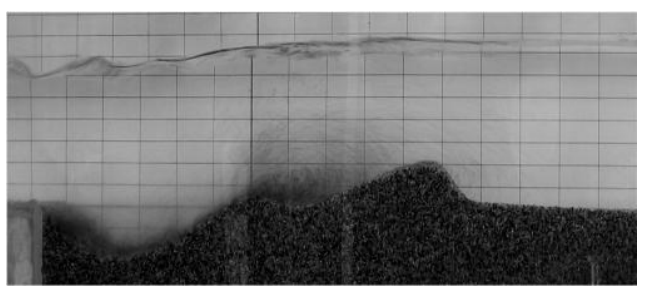

(f)

Fig. 11. Sequence from run no. $7: 1^{\text {st }}$ complete cycle and beginning of the $2^{\text {nd }}$ bed jet phase.

First bed jet phase: a) $t=31 \mathrm{~s}$; b) $t=61 \mathrm{~s}$. First surface jet phase: c) $t=92 \mathrm{~s}$; d) $t=122 \mathrm{~s}$; e) $t=$ $153 \mathrm{~s}$. Second bed jet phase: f) $t=164 \mathrm{~s}$.

The duration of each complete cycle (bed and surface jet) depends rather strongly on the flow conditions. Figure 11 and Fig. 12 show the first complete cycle and the beginning of the second bed 
jet phase of two tests (no. 7 and 8). If compared to the already shown test 14 , these tests are characterized by smaller non-dimensional apron lengths and, respectively, by smaller or by the same non-dimensional tailwater depths (Table 1).

For a given run, the duration of each complete cycle and of each phase within a cycle (bed jet or surface jet phase) varies with no regularity. The average cycle duration $\Delta t$ together with the percentages of bed jet flow $\Delta t_{B} \%$ and of surface jet flow $\Delta t_{S} \%$ are given in Table 2 for each 8-hour run.

It has been observed that the duration of the bed jet phases is on average roughly constant during each test, while the duration of the surface jet phases tends to increase slightly with time; furthermore, the longer the jet is attached to the channel bed, the longer the following surface jet phase and viceversa (nevertheless, exceptions to this intuitive rule have been noticed).

Comparisons of tests with approximately equal $l / y_{0}$ (as for example runs no. 1, 2, 4, 5, 7, 8, 12, 15, 18, 22, 23 and 24) suggest that, for fixed $F_{0}$, intermediate $y_{T} / y_{0}$ ratios lead to bed-surface jet flows. When the normalized tailwater depth is large, bed jet flows are expected while surface jet flows develop under low $y_{T} / y_{0}$. Moreover, the higher $F_{0}$, the larger the $y_{T} / y_{0}$ interval characterized by the jet flicking. Finally, again for fixed $l / y_{0}$ and $F_{0}$, the larger the normalized tailwater depth, the longer the average cycle period in bed-surface jet flows.

The jet cyclic behavior gives to the bed profile a less regular shape than that found in steady flow regimes.

Table 2 Average temporal characteristics of flow cycles for bed-surface jet regime tests

\begin{tabular}{|c|c|c|c|}
\hline Run & $\Delta t[\mathrm{~s}]$ & $\Delta t_{B} \%$ & $\Delta t_{S} \%$ \\
\hline 1 & 1600 & $9 \%$ & $91 \%$ \\
\hline 4 & 410 & $8 \%$ & $92 \%$ \\
\hline 5 & 12900 & $44 \%$ & $56 \%$ \\
\hline 7 & 230 & $8 \%$ & $92 \%$ \\
\hline 8 & 3700 & $47 \%$ & $53 \%$ \\
\hline 9 & 4100 & $21 \%$ & $79 \%$ \\
\hline 14 & 900 & $10 \%$ & $90 \%$ \\
\hline 17 & 500 & $7 \%$ & $93 \%$ \\
\hline
\end{tabular}

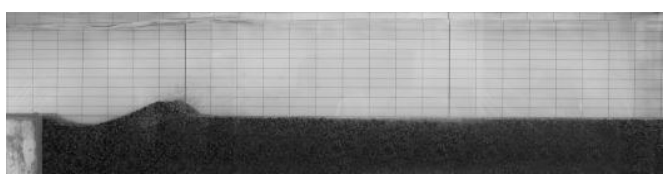

(a)

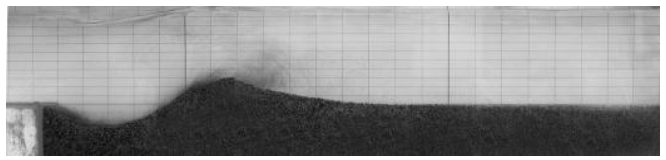

(b)

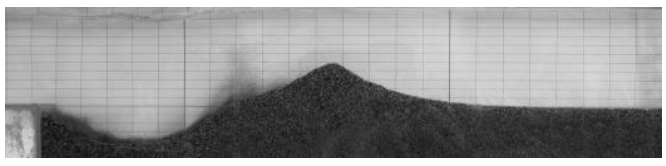

(c)

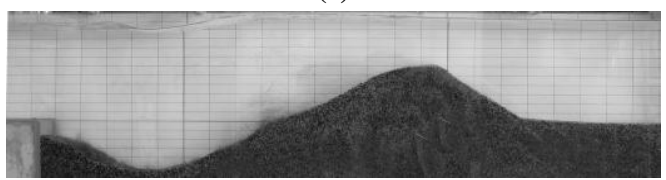

(d)

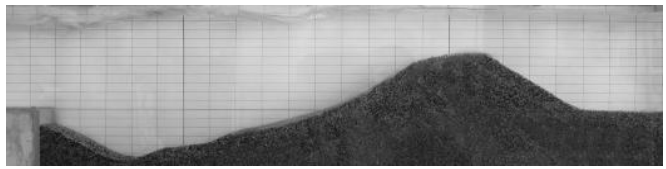

(e)

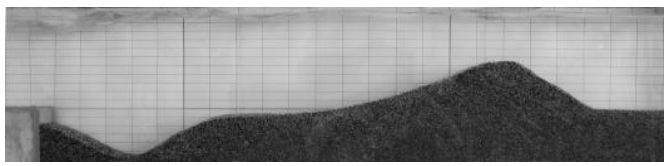

(f)

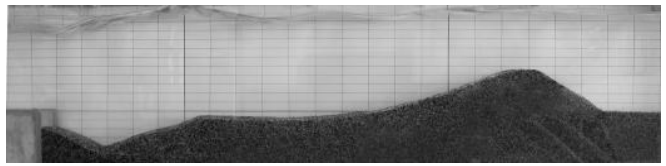

(g)

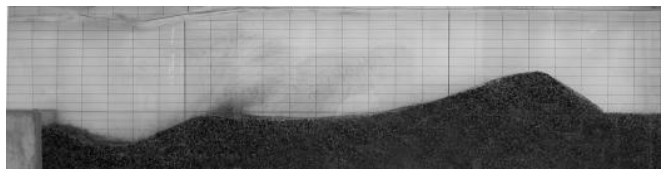

(h)

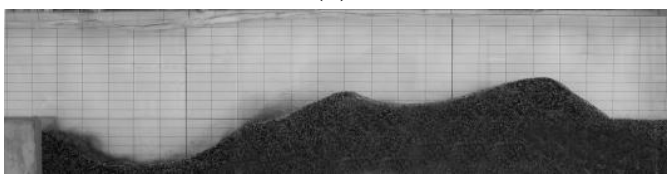

(i)

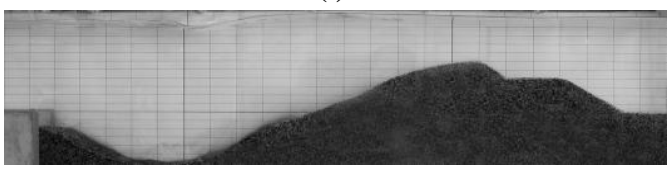

(j)

Fig. 12. Sequence from run no. 8: $1^{\text {st }}$ complete cycle and the beginning of the $2^{\text {nd }}$ bed jet phase. $1^{\text {st }}$ bed jet phase: (a) $t=11 \mathrm{~s}$; (b) $t=60 \mathrm{~s}$; (c) $t=$ $245 \mathrm{~s}$; (d) $t=1195 \mathrm{~s}$. $1^{\text {st }}$ surface jet phase: (e) $t=$ $1931 \mathrm{~s}$; (f) $t=2124 \mathrm{~s}$; (g) $t=2706 \mathrm{~s} .2^{\text {nd }}$ bed jet phase: (h) $t=2973 \mathrm{~s}$; (i) $t=3202 \mathrm{~s}$; (j) $t=4203 \mathrm{~s}$. 


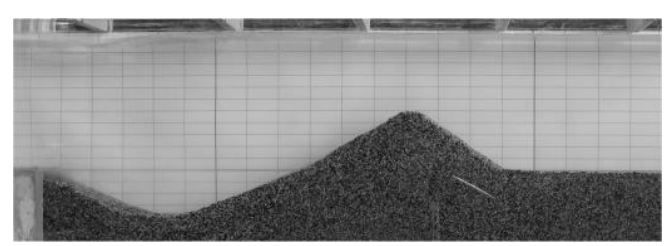

(a)

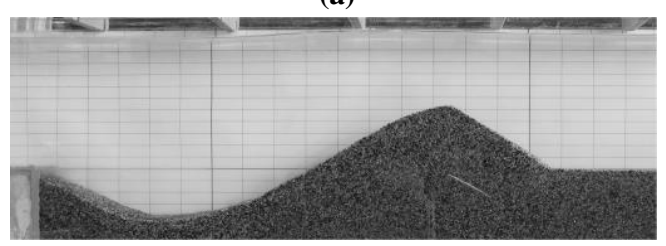

(b)

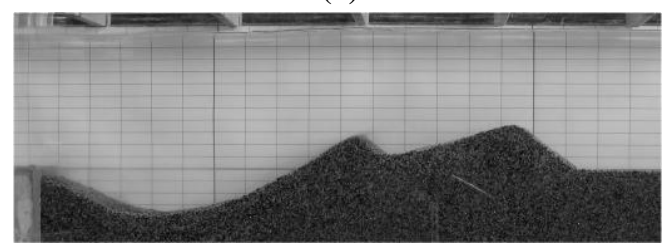

(c)

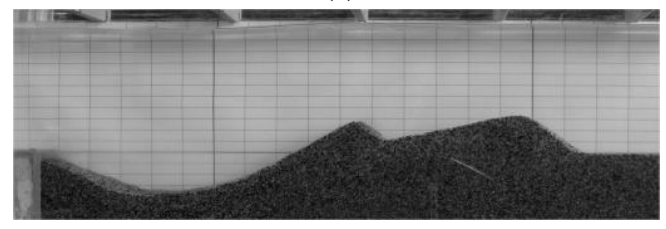

(d)

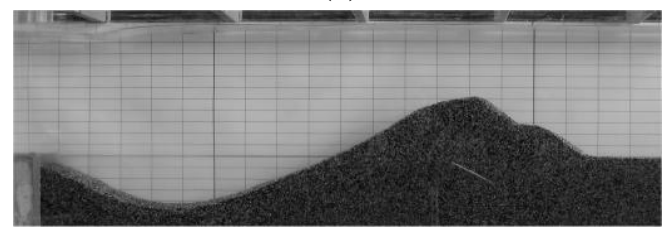

(e)

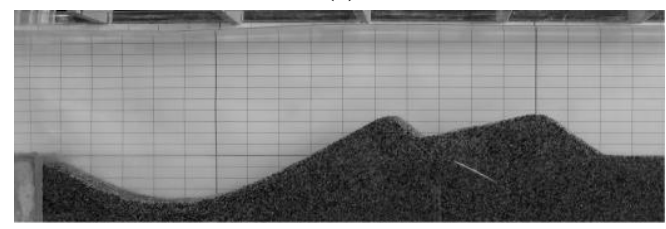

(f)

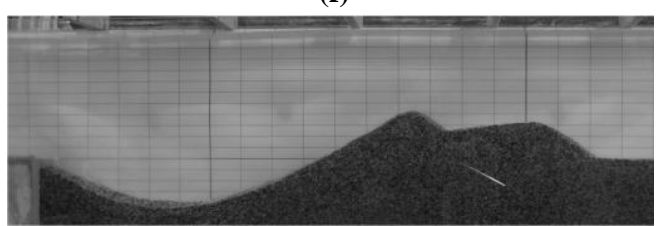

(g)

Fig. 13. Bed profile at the end of the bed jet phase for different cycles of run no. 9: (a) $t=$ $1165 \mathrm{~s}$ (cycle no. 1); (b) $t=2400 \mathrm{~s}$ (cycle no. 2); (c) $t=7975 \mathrm{~s}$ (cycle no. 3); (d) $t=11641 \mathrm{~s}$ (cycle no. 4); (e) $t=14700 \mathrm{~s}$ (cycle no. 5); (f) $t=21000 \mathrm{~s}$

(cycle no. 6); (g) $t=25117 \mathrm{~s}$ (cycle no. 7).

Two different dunes may be observed during the bed evolution: a main dune, at larger $x$, and a secondary dune, closer to the scour hole and generated by the bed jet flow. The main dune is still present at the end of the surface jet phase while the secondary one reaches its maximum height at the end of the bed jet phase, but collapses in the scour hole during the following surface jet phase. In a given run, the secondary dune at the end of each bed jet phase is in general systematically higher (or lower) than the primary one. However, in some cases (for instance, test no. 9, Fig. 13), the maximum height shifts from one dune to the other cycle by cycle. As shown in Fig. 13.a, Fig. 13.b and Fig. 13.e, after an intense bed jet phase, the secondary dune may even completely overlap the primary one.

The description of the time evolution of the bedprofile characteristics is therefore more complex than for stable cases. However, it can be noted that the maximum values of the scour depth $h_{S, \max }$ and of the secondary dune height are still reached at the end of a bed jet phase and that the longer this phase the larger the mentioned geometric scales.

When analyzing run no. 14, which is mostly characterized by surface-jet phases, and focusing only on cycles characterized by relatively long bed jet phases, it can be noticed that scour hole profiles at the end of these bed jet phases are nearly equal (Fig. 14).

This result points out that, for this kind of regime, the maximum value of scour depth (and, in the same way, of the secondary dune height) does not seem to be reached asymptotically.

Analogous considerations can be repeated for other bed-surface jet cases, even when the average cycle duration is much larger (run no. 9, Fig. 13 and Fig. 15 ) or when it is shorter and the evolution of the primary dune resembles closely the one observed in the surface jet regime (run no. 7, Fig. 16 and Fig.17).

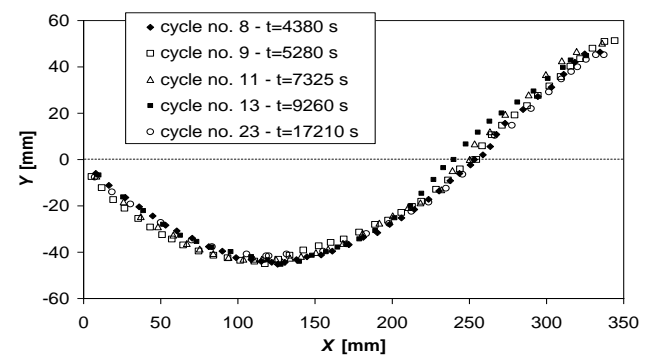

Fig. 14. Dimensional bed profiles at the end of the bed jet phase for five cycles in test no. 14 .

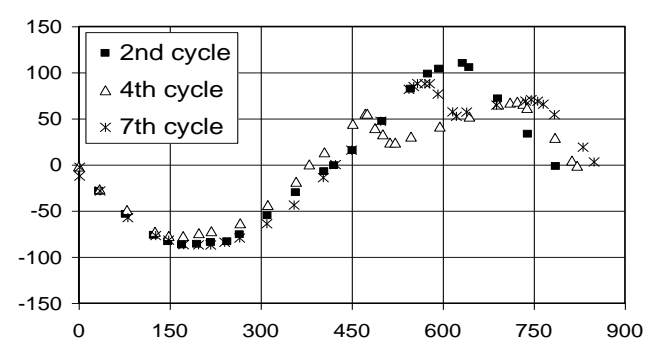

Fig. 15. Dimensional bed profiles $y$ vs. $x$ (in mm) after the bed jet phase for different cycles of run no. 9. Profiles are carried out processing frames b), d) and g) of Fig. 13. 
Table 3 reports maximum scour depths $h_{S, \max }$ measured for bed-surface jet regime tests as discussed above. Comparison is made with scour depths computed using the classical formulae by Schoklitsch:

$$
h_{s, \max , \infty}=0.378 y_{H}^{0.5} q^{0.35}
$$

and Shalash :

$$
h_{s, \max \infty}=9.65 \Delta y^{0.5} q^{0.6} d_{G}^{-0.4}\left(\frac{1.5 \Delta y}{l}\right)^{0.6}-y_{T}
$$

reported in Breusers \& Raudkivi (1991), being $\Delta y=$ $y_{H}-y_{T}$ and $q$ the flow rate per unit width; all quantities are expressed in SI units, except $d_{G}$ which should be in $\mathrm{mm}$.

Equation (3) is based on model tests with short apron length $(l / \Delta y=1.5)$ but it gives acceptable estimates of the magnitude of observed scour depths. Nevertheless, contrary to expectations, the discrepancies between measured and calculated results do not decrease as $l / \Delta y$ approaches 1.5: for example in run no. 8 (whose $l / \Delta y$ ratio is the closest to 1.5 among the values reported in Table 3 ) the measured scour depth is about twice as the predicted one.

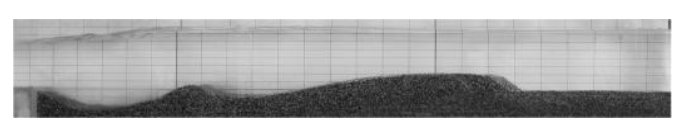

(a)

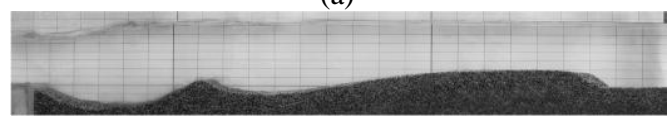

(b)

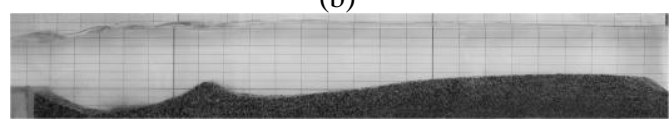

(c)

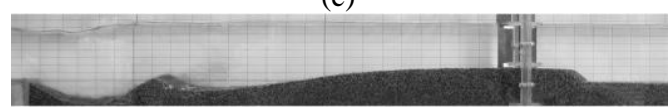

(d)

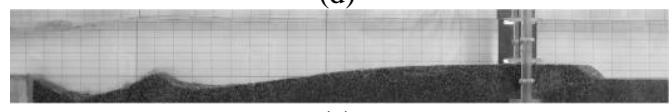

(e)

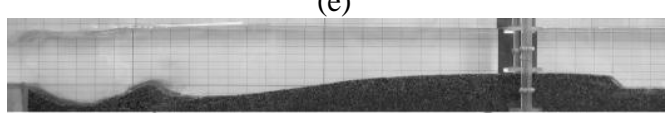

(f)

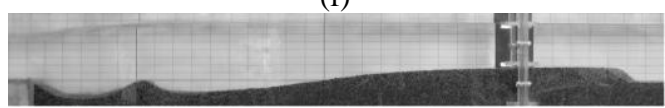

(g)

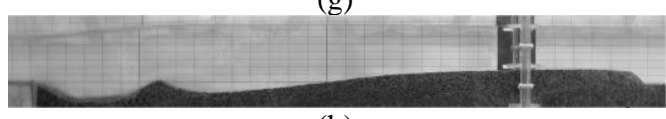

(h)

Fig. 16. Bed profile at the end of the bed jet phase for different cycles of run no. 7 (the picture zoom in frames a-c is larger than in frames d-h): (a) $t=2801 \mathrm{~s}$ (cycle no. 19); (b) $t=$ $5776 \mathrm{~s}$ (cycle no. 32); (c) $t=8202 \mathrm{~s}$ (cycle no. 43); (d) $t=17662 \mathrm{~s}$ (cycle no. 83); (e) $t=20329 \mathrm{~s}$ (cycle no. 93); (f) $t=23022$ s (cycle no. 103); (g) $t=$ 26031 s (cycle no. 114); (h) $t=27397$ s (cycle no. 119).

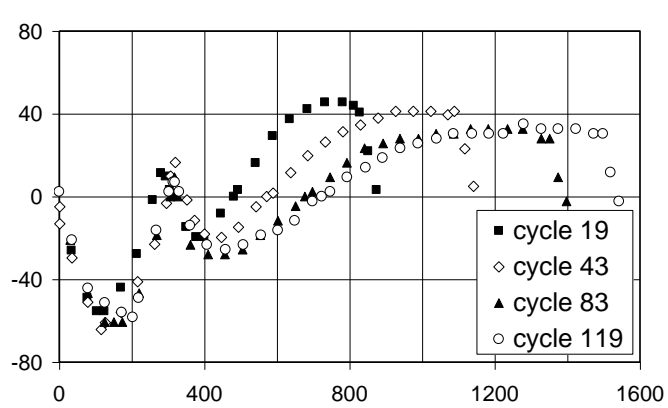

Fig. 17. Dimensional bed profiles $y$ vs. $x$ (in mm) after the bed jet phase for different cycles of run no. 7. Profiles are carried out by processing frames a), c), d) and h) of Fig. 16.

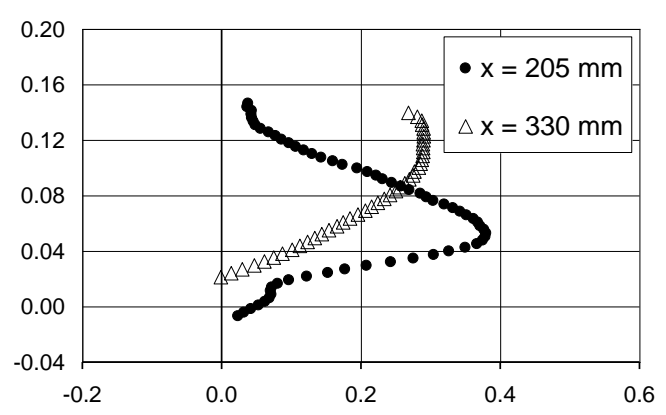

(a)

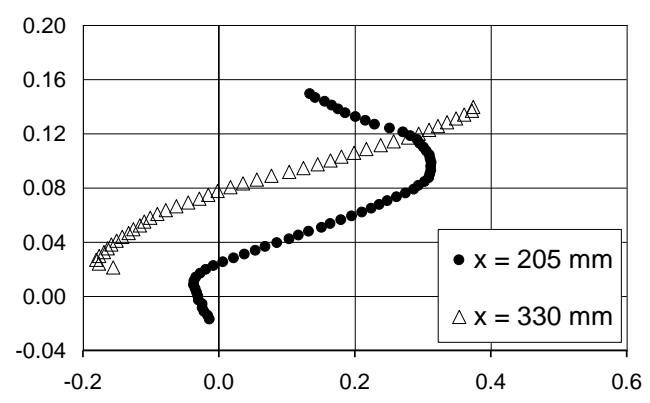

(b)

Fig. 18. ADV Vertical profiles of $u$ (in $\mathrm{m} / \mathrm{s}$ ) vs. $y$ (in $\mathrm{m}$ ) at different $x$ positions, for test no. 14 (bed-surface jet scouring regime): a) $x / l=0.41$; b) $x / l=0.66$.

Table 3 Maximum scour depths for bed-surface jet regime tests.

\begin{tabular}{|c|c|c|c|c|}
\hline Run & $\begin{array}{c}h_{S, M A X} \\
\text { measured }\end{array}$ & $\begin{array}{c}h_{S, \max , \infty} \\
\text { Eq. (3) }\end{array}$ & $\begin{array}{c}h_{S, \max , \infty} \\
\text { Eq. (4) }\end{array}$ & $l / \Delta y$ \\
\hline$[\mathrm{mm}]$ & {$[\mathrm{mm}]$} & {$[\mathrm{mm}]$} & \\
\hline 1 & 38 & 35 & - & 15.6 \\
\hline 4 & 54 & 46 & - & 6.0 \\
\hline 5 & 113 & 56 & - & 4.5 \\
\hline 7 & 65 & 58 & 61 & 3.2 \\
\hline 8 & 131 & 67 & 41 & 2.6 \\
\hline 9 & 91 & 59 & - & 11.9 \\
\hline
\end{tabular}


On the other hand Eq. (4), which explicitly takes into account the apron length, gives negative values (i.e. predicts no scour) for almost all the bedsurface jet regime tests of Table 3; moreover, it seems to give better results for smaller $l / \Delta y$ ratios (tests no. 7 and 8), again in disagreement with expectations.

Velocity profiles during both phases of the bedsurface jet cycle have been obtained for test no. 14 by averaging several ADV measurements during each phase. The different jet patterns above the scour hole at $x / l=0.41(\mathrm{x}=205 \mathrm{~mm})$ are clearly visible in Fig. 18.a: during the surface jet phase the flow shifts towards the free surface and a recirculation region appears close to the erodible bed, while during the bed jet phase the velocity peak is closer to the bed and the scour process is consequently more intense. These differences extend downstream ( $x=330 \mathrm{~mm}$; Fig. 18.b): in the surface jet phase, a large backflow region is present also above the dune, contributing, as previously observed, to the collapse of the secondary dune into the scour hole.

\section{CONCLUSIONS}

The local scour of a non-cohesive sand bed downstream of an apron caused by a 2D horizontal jet flowing from a sluice gate was studied experimentally in a laboratory channel. When the tailwater depth is large enough to guarantee a submerged hydraulic jump downstream of the gate, but it is only a few times the gate opening, three distinct scouring regimes can arise.

In the surface jet regime, the jet tends to reach the free surface at the end of the apron and the scour hole and the dune develop mainly horizontally, following an elongated profile with low vertical dimensions. In the bed jet regime the jet adheres to the erodible bed and the resulting scour hole and dune are shorter, while their vertical dimensions are larger than in the previous case. An intermediate regime exists in which an unsteady cyclic flow onsets, the jet switching intermittently between the previous flow regimes: the resulting scour hole and dune shapes are also unsteady; in this case the maximum scour depth is not reached asymptotically but at the end of the more intense bed jet phases.

At least three non-dimensional parameters (when neglecting the effect of the Reynolds number and the grain size) are needed to predict the flow regime: the densimetric Froude number $F_{0}$, the normalized apron length $l / y_{0}$ and the normalized tailwater depth $y_{T} / y_{0}$.

Comparison of tests with approximately equal $l / y_{0}$ (Fig. 19) suggests that, for fixed $F_{0}$, intermediate $y_{T} / y_{0}$ ratios lead to bed-surface jet flows. When the normalized tailwater depth is large, bed jet flows are expected while surface jet patterns develop under low $y_{T} / y_{0}$. Moreover, the higher $F_{0}$, the larger the $y_{T} / y_{0}$ interval characterized by the jet flicking. Finally, again for fixed $l / y_{0}$ and $F_{0}$, the larger the normalized tailwater depth, the longer the average cycle period in flicking jet flows. The classical formulae by Schoklitsch and Shalash fail to reliably estimate the maximum scour depth for bed-surface jet regime flows.

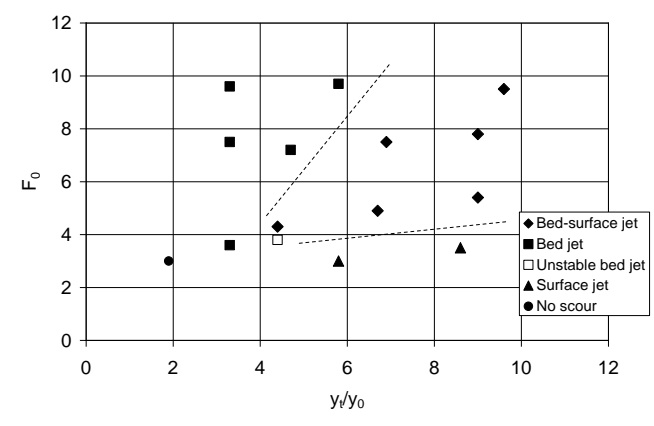

Fig. 19. Different scouring regimes occurring as function of $y_{T} / y_{0}$ and $F_{0}$ for normalized apron lengths in the range $8<l / y_{0}<11$.

LDA and ADV velocity measurements, together with photographs and quantitative bed profiles evaluations, are provided for selected experiments: these data may be useful for the validation of numerical models able to simulate the interaction of free-surface flows with non-cohesive granular beds.

\section{REFERENCES}

Aderibigbe, O. and N. Rajaratnam (1998). Effect of sediment gradation on erosion by plane turbulent wall jets. Journal of Hydraulic Engineering 124 (10), 1034-1042.

Adduce C. and M. La Rocca (2006). Local scouring due to turbulent water jets downstream of a trapezoidal drop: Laboratory experiments and stability analysis. Water Resources Research 42, W02405, doi:10.1029/2005WR004139.

Adduce C. and G. Sciortino (2006). Scour due to a horizontal turbulent jet: numerical and experimental investigation. Journal of Hydraulic Research 44 (5), 663-673.

Ali K. H. M. and S. Y. Lim (1986). Local scour caused by submerged jets. Proceedings of the Institution of the Civil Engineers - Part II 81, 607-645.

Breusers H. N. C. and A. J. Raudkivi (1991). Scouring. Rotterdam, The Netherlands: Balkema.

Chatterjee S. S. and S. N. Ghosh (1980). Submerged horizontal jet over erodible jet. Journal of the Hydraulics Division ASCE 106 (HY11), 1765-1782.

Chatterjee S. S., S. N. Ghosh and M. Chatterjee (1994). Local scour due to submerged horizontal jet. Journal of Hydraulic Engineering 120 (8), 973-992.

Dey S. and A. Sarkar (2006). Scour downstream of an apron due to submerged horizontal jets. Journal of Hydraulic Engineering 132 (3), 
P. Espa and S. Sibilla. / JAFM, Vol. 7, No. 4, pp. 611-624, 2014.

246-257.

Dey S. and A. Sarkar (2008). Characteristics of submerged jets in evolving scour hole downstream of an apron. Journal of Engineering Mechanics 134 (11), 927-936.

Hoffmans G. J. C. M. and H. J. Verheij (1997). Scour Manual. Rotterdam, The Netherlands, Balkema.

Johnston A. J. (1990). Scourhole developments in shallow tailwater. Journal of Hydraulic Research 28 (3), 341-354.

Johnston A. J. and A. R. Halliwell (1986). Jet behavior in shallow receiving water. Proceedings of the Institution of the Civil Engineers - Part II 81, 549-568.

Johnston, A. J. and A. R. Halliwell (1987). Discussion on Paper: Local scour caused by submerged jets (by Ali, K.H.M. and Lim, S.Y.). Proceedings of the Institution of the Civil Engineers - Part II 83, 875-886.

Manenti S., S. Sibilla, M. Gallati, G. Agate and R. Guandalini (2012). SPH simulation of sediment flushing induced by a rapid water flow. Journal of Hydraulic Engineering, 138 (3), 272-284.

Nik Hassan N. M. K. and R. Narayanan (1985). Local scour downstream of an apron. Journal of Hydraulic Engineering 111 (11), 13711385.

Rajaratnam N. (1976). Turbulent jets. Amsterdam, The Netherlands, Elsevier.
Rajaratnam N. (1981). Erosion by plane turbulent jets. Journal of Hydraulic Research 19 (4), 339-358.

Rajaratnam N. and R. K. Mac Dougall (1983). Erosion by plane wall jets with minimum tailwater. Journal of Hydraulic Engineering, 109 (7), 1061-1064.

Razmi A., B. Firoozabadi and G. Ahmadi (2009). Experimental and numerical approach to enlargement of performance of primary settling tanks. Journal of Applied Fluid Mechanics, 2 (1), 1-12.

Sibilla S. (2008). A SPH-based method to simulate local scouring. Proceedings of the $19^{\text {th }}$ IASTED International Conference on Modelling and Simulation - MS2008, Ville de Quebec, Canada, 9-14.

Sibilla S. and P. Espa (2008). SPH numerical simulation of local scour downstream of an apron. Proceedings of the $4^{\text {th }}$ International Conference on Fluvial Hydraulics - River Flow 2008, Çeşme, Turkey, 2067-2073.

Souza L. B. S., H. E. Schulz, S. M. Villela, J. S. Gulliver and L. B. S. Souza (2010). Experimental study and numerical simulation of sediment transport in a shallow reservoir. Journal of Applied Fluid Mechanics, 3 (2), 921.

Vollmer, S. and M. G. Kleinhans (2007). Predicting incipient motion, including the effect of turbulent pressure fluctuations in the bed. Water Resources Research, 43, W05410. 